\title{
BIAYA LANGSUNG DAN TIDAK LANGSUNG PADA PENYAKIT HIPERTENSI : NARRATIVE REVIEW
}

\section{Direct And Indirect Costs Of Hypertension Disease : Narrative Review}

\section{Budi Respati Nur \\ Mulianingsih '}

Dwi Endarti ${ }^{2 *}$

\section{Anna Wahyuni Widayanti $^{2}$}

IMagister Manajemen Farmasi, Fakultas Farmasi, Universitas Gadjah Mada, Yogyakarta, Daerah Istimewa Yogyakarta, Indonesia

2*Departemen Farmasetika, Fakultas Farmasi, Universitas Gadjah Mada, Yogyakarta, Daerah Istimewa Yogyakarta, Indonesia

*email : endarti_apt@ugm.ac.id

\begin{abstract}
Abstrak
Hipertensi menjadi masalah kesehatan karena meningkatkan mortalitas dan morbiditas serta beban biaya kesehatan di Indonesia. Analisis Cost of Illness (COI) perlu dilakukan dari perspektif yang berbeda agar memberi informasi tambahan bagi pembuat kebijakan akan dampak ekonomi yang ditimbulkan oleh penyakit hipertensi. Tujuan penelitian ini adalah menjelaskan komponen penyusun biaya kesehatan pada penyakit hipertensi berdasarkan perspektif yang berbeda yaitu pasien, pembayar dan penyedia layanan kesehatan. Hasil penelitian ini diketahui bahwa biaya medis dan non medis langsung merupakan komponen terbesar dari biaya kesehatan. Biaya obat, konsultasi dokter, pemeriksaan penunjang (tes laboratorium), tenaga kesehatan yang merawat, administrasi menjadi komponen terbesar penyusun biaya medis langsung. Biaya perjalanan dan biaya makan merupakan komponen biaya non medis langsung. Produktivitas yang hilang dari pasien atau pengasuh dihitung dengan pendekatan human capital dan menempati porsi pengeluaran biaya kesehatan sebagai biaya tidak langsung. Hal ini dapat membantu pemerintah dan peneliti lainnya memiliki kesamaan persepsi dalam menentukan komponen biaya kesehatan yang diteliti. Penelitian tentang COI dapat membantu pemerintah mengendalikan penyakit hipertensi dengan upaya promotif dan preventif serta meningkatkan program kesehatan publik pemerintah bagi penyakit hipertensi.
\end{abstract}

\section{Kata Kunci:}

Cost of illness

Biaya Langsung

Biaya Tidak Langsung

Hipertensi

Keywords:

Cost of illness

Direct Cost

Indirect Cost

Hypertension

\begin{abstract}
Hypertension is a health problem that increases mortality and morbidity as well as the economic burden of healthcare in Indonesia. Analysis of Cost of Illness (COI) must be conducted from different perspectives in order to provide additional information for policy makers about the economic impact caused by hypertension. The purpose of this review is to explain the components of healthcare costs in hypertension based on different perspectives, namely patient, payer and healthcare providers. The results of this study show that direct and non-medical costs are the largest component of healthcare costs. Drug, doctor consultations, supporting examinations (laboratory tests), healthcare workers, administration costs are the biggest components of direct medical costs. Travel and food expenses are components of direct non-medical costs. The lost productivity of patients or caregivers is calculated using the human capital approach and occupies the portion of health expenses as indirect costs. This can help the government and other researchers have the same perception in determining the components of the health costs under study. Study of $\mathrm{COI}$ can help the government to control hypertension with promotive and preventive efforts and improve the government's public health program for hypertension.
\end{abstract}




\section{PENDAHULUAN}

Hipertensi menjadi silent killer karena terjadi kenaikan tekanan darah sistolik, diatolik atau keduanya tanpa gejala yang nampak sehingga meningkatkan mortalitas, morbiditas serta beban biaya kesehatan (Adane et al., 2020). Prevalensi hipertensi secara global di negara berpenghasilan rendah dan menengah diperkirakan mencapai I,I 3 miliar individu dan prevalensi hipertensi tertinggi yaitu sebesar $27 \%$ berada di negara Afrika serta prevalensi terendah diraih oleh negara Amerika sebesar 18\% (World Health Organization, 2019). Riset Kesehatan Dasar (Riskesdas) 2018 menyatakan bahwa prevalensi penderita hipertensi di Indonesia mencapai 34,1\% dari jumlah penduduk sebesar 260 juta. Data Badan Penyelenggara Jaminan Sosial (BPJS) Kesehatan menggambarkan bahwa peningkatan biaya pelayanan hipertensi terus menerus terjadi setiap tahun yaitu pada tahun 2016 sebesar 2,8 triliun rupiah, tahun 2017 dan 2018 mencapai 3 triliun rupiah (Kementerian Kesehatan Republik Indonesia, 2019).

Di Indonesia, BPJS Kesehatan bersama dengan fasilitas kesehatan melakukan upaya promotif dan preventif melalui Program Pengelolaan Penyakit Kronis (Prolanis). Hal ini bertujuan untuk memenuhi pemeliharaan kesehatan peserta dengan penyakit hipertensi sehingga meningkatkan kualitas hidup tanpa mengalami beban finansial (Badan Penyelenggara Jaminan Sosial Kesehatan, 2019). Namun, berdasarkan penelitian yang dilakukan di Puskesmas Jetis Yogyakarta diketahui bahwa kunjungan pasien hipertensi yang tercakup dalam Prolanis pada tahun 2017 menurun sebanyak 332 pasien (Meiriana et al., 2019). Penelitian lainnya yang dilakukan di Puskesmas Kabupaten Pamekasan menunjukkan bahwa sebanyak 65\% pasien hipertensi Penerima Bantuan luran (PBI) Jaminan Kesehatan Nasional (JKN) masih mengeluarkan biaya pelayanan kesehatan (Istiqomah \& Rochmah, 2016). Penelitian di Nigeria menemukan bahwa sebesar 16,4\% rumah tangga melakukan pengeluaran biaya kesehatan dan mampu mengakibatkan peningkatan kemiskinan sebesar 0,8\% dari I,3 juta penduduk Nigeria (Aregbeshola \& Khan, 2018).

Analisis Cost of Illness (COI) perlu dilakukan untuk memperkirakan beban ekonomi yang ditimbulkan oleh penyakit hipertensi pada individu, masyarakat dan negara. Data COI dapat menjadi informasi tambahan bagi pembuat kebijakan untuk menetapkan kebijakan di sektor kesehatan agar pemanfaatan sumber daya menjadi efektif dan efisien. Pada COI, biaya dikategorikan menjadi biaya langsung, tidak langsung dan intangible (Le et al., 2012). Perspektif dibangun untuk menjelaskan biaya kesehatan yang dikeluarkan oleh pengguna dan pemberi pelayanan kesehatan (Adane et al., 2020).

Komponen penyusun biaya langsung dan tidak langsung perlu dipahami dari perspektif yang berbeda. Saat ini masih sedikit review tentang COI penyakit hipertensi dan terdapat perbedaan pemahaman dalam mengidentifikasi biaya. Review ini membantu memberi gambaran tentang masalah yang terjadi, membahas pemilihan metode farmakoekonomi dan mengidentifikasi masalah yang belum diteliti. Tujuan penelitian ini adalah mengidentifikasi komponen penyusun biaya kesehatan pada penyakit hipertensi berdasarkan perspektif yang berbeda yaitu pasien, pembayar dan penyedia layanan kesehatan serta untuk mengetahui besarnya biaya langsung dan tidak langsung.

\section{METODOLOGI}

Pengerjaan review ini melalui beberapa tahap. Pertama, menentukan topik dan menetapkan kriteria inklusi dan eksklusi. Kedua, mencari literatur dari berbagai macam database menggunakan beberapa kata kunci dalam bahasa Inggris dan bahasa Indonesia. Ketiga, mengidentifikasi artikel melalui pencarian database dan melakukan skrining terhadap judul dan abstrak. Keempat, memilih literatur yang dapat diakses secara penuh dan melakukan review. 


\section{Sumber Data}

Pencarian literatur dilakukan pada bulan Maret-Mei 2021 yang diperoleh dari database Google Scholar, PubMed dan Semantic Scholar. Beberapa kata kunci dalam bahasa Inggris dan bahasa Indonesia yang digunakan untuk pencarian literatur antara lain : "cost of illness hypertension", "economic burden hypertension", "cost hypertension", “cost hypertension", "biaya pengobatan hipertensi”, "biaya medik langsung hipertensi”, “biaya tidak langsung hipertensi”.

\section{Kriteria Inklusi dan Eksklusi}

Literatur yang diperoleh akan diseleksi sesuai dengan kriteria inklusi antara lain artikel ditulis dalam bahasa Inggris dan/ atau bahasa Indonesia, publikasi artikel pada tahun 2008 - 2021, artikel membahas tentang biaya langsung dan tidak langsung dan artikel dapat diakses penuh. Artikel dalam bentuk systematic review atau meta analisis, letter dan comment menjadi kriteria eksklusi.

\section{Seleksi Literatur}

Artikel dianalisis dan dipilih oleh peneliti dengan bantuan Zotero sebagai reference manager. Artikel dipilih berdasarkan perspektif yang digunakan untuk menganalisis biaya dan komponen penyusun pengeluaran biaya kesehatan. Peneliti mengkaji data biaya atau beban ekonomi yang ditimbulkan penyakit hipertensi.

\section{HASIL DAN PEMBAHASAN}

\section{Penemuan Literatur}

Pencarian literatur pada database Google Scholar, PubMed dan Semantic Scholar terkait beban ekonomi penyakit hipertensi menghasilkan 1047 artikel. Penilaian kualitas dan seleksi artikel dilakukan meliputi kajian abstrak dan judul sehingga menyisakan 12 artikel. Tabel I menyajikan ringkasan review artikel.

\section{Perspektif}

Berdasarkan 12 artikel yang diringkas pada tabel I, diketahui bahwa 4 artikel (33,3\%) dilakukan di Indonesia (Baroroh \& Fathonah, 2017; Etika et al., 2020; Istiqomah \& Rochmah, 2016; Utari \& Rochmah, 2017), 2 artikel (16,7\%) dilakukan di Ethiopia (Adane et al., 2020; Zawudie et al., 2020), 2 artikel (16,7\%) dilakukan di Malaysia (Alefan et al., 2009; Suhil et al., 2010), I artikel (8,3\%) masing-masing dilakukan di Cameroon (Aminde et al., 2021), Pakistan (Aslam et al., 20I8), Vietnam (Nguyen et al., 20I4) dan China (Le et al., 2012). Sebagian besar artikel (66,7\%) menggunakan perspektif pasien, 25\% menggunakan perspektif penyedia layanan kesehatan dan 8,3\% menggunakan perspektif pembayar.

Perspektif dapat dilihat dari segi masyarakat, pasien, penyedia layanan kesehatan dan pembayar. Pembagian perspektif ini penting untuk membantu peneliti mengidentifikasi biaya dengan tepat serta memberikan gambaran mengenai pelaku pengeluaran biaya kesehatan ataupun pemberi layanan kesehatan (Rascati, 2014). Tabel II menyajikan kategori biaya kesehatan berdasarkan masing-masing perspektif.

Perspektif masyarakat merupakan pendekatan yang paling tepat dan komprehensif. Hal ini dikarenakan pengeluaran biaya kesehatan oleh masyarakat terdiri dari biaya asuransi kesehatan, biaya untuk pasien, biaya untuk penyedia layanan kesehatan, biaya di sektor lain dan biaya tidak langsung seperti produktivitas yang hilang. Perspektif masyarakat jarang digunakan karena sulit dilakukan dan membutuhkan banyak waktu untuk menghitung keseluruhan biaya secara rinci. Perspektif pasien dapat dilakukan dengan menghitung pengeluaran biaya secara langsung dari kantong pasien (out-ofpocket) seperti membayar sebagian biaya yang tidak ditanggung asuransi kesehatan, pendapatan yang hilang karena sakit dan biaya perjalanan. Penyedia layanan kesehatan terdiri atas rumah sakit dan fasilitas kesehatan tingkat pertama. Perspektif penyedia layanan kesehatan memperkirakan biaya perawatan pasien. 
Perspektif pembayar (pihak asuransi kesehatan) memperkirakan biaya yang dibayar ke penyedia layanan kesehatan berdasarkan layanan kesehatan yang telah diberikan (Rascati, 2014).

\section{Komponen Biaya}

Berdasarkan perspektif yang dipilih, kita dapat menentukan komponen penyusun biaya kesehatan yang harus dihitung antara lain biaya langsung dan tidak langsung. Biaya langsung merupakan biaya yang timbul akibat konsumsi sumber daya untuk mengobati penyakit seperti pengeluaran untuk kebutuhan medis dan pengobatan (Le et al., 20I2). Biaya langsung dikategorikan menjadi 2 macam yaitu biaya medis dan non medis langsung. Biaya tidak langsung merupakan biaya yang timbul karena berpindahnya pilihan sehingga mengakibatkan hilangnya produktivitas pasien/ pengasuh (Afroz et al., 20I8). Menurut Le et al. (20I2), biaya tidak langsung dikategorikan menjadi biaya morbiditas berupa pendapatan yang hilang akibat kecacatan atau absen kerja dan biaya mortalitas berupa kematian

dini.

Tabel I. Review cost of illness untuk hipertensi berdasarkan perspektif dan komponen biaya

\begin{tabular}{|c|c|c|c|c|c|c|}
\hline \multirow[b]{2}{*}{ No } & \multirow[b]{2}{*}{$\begin{array}{l}\text { Nama Peneliti } \\
\text { dan Tahun }\end{array}$} & \multirow[b]{2}{*}{ Lokasi } & \multirow[b]{2}{*}{ Perspektif } & \multicolumn{3}{|c|}{ Komponen Biaya } \\
\hline & & & & $\begin{array}{l}\text { Biaya Medis } \\
\text { Langsung }\end{array}$ & $\begin{array}{l}\text { Biaya Non } \\
\text { Medis } \\
\text { Langsung }\end{array}$ & $\begin{array}{l}\text { Biaya Tidak } \\
\text { Langsung }\end{array}$ \\
\hline I & Adane et al., 2020 & Ethiopia & Pasien & obat, diagnosis & perjalanan & $\begin{array}{l}\text { Produktivitas yang } \\
\text { hilang }\end{array}$ \\
\hline 2 & Alefan et al., 2009 & Malaysia & Pasien & $\begin{array}{l}\text { obat, laboratorium, } \\
\text { jasa dokter, apoteker } \\
\text { dan perawat }\end{array}$ & perjalanan & $\begin{array}{l}\text { Produktivitas yang } \\
\text { hilang }\end{array}$ \\
\hline 3 & Aminde et al., 2021 & Cameroon & $\begin{array}{c}\text { Penyedia layanan } \\
\text { kesehatan }\end{array}$ & $\begin{array}{l}\text { konsultasi, } \\
\text { laboratorium, } \\
\text { pemeriksaan } \\
\text { penunjang, obat, rawat } \\
\text { inap }\end{array}$ & - & - \\
\hline 4 & Aslam et al., 2018 & Pakistan & Pasien & $\begin{array}{l}\text { obat, jasa dokter, } \\
\text { laboratorium }\end{array}$ & perjalanan & $\begin{array}{l}\text { Produktivitas yang } \\
\text { hilang dengan absen } \\
\text { kerja }\end{array}$ \\
\hline 5 & $\begin{array}{l}\text { Baroroh dan } \\
\text { Fathonah, } 2017\end{array}$ & Indonesia & Pembayar & obat & - & - \\
\hline 6 & Etika et al., 2020 & Indonesia & Pasien & $\begin{array}{l}\text { pendaftaran, jasa } \\
\text { dokter, obat }\end{array}$ & Biaya perjalanan & $\begin{array}{l}\text { Pendapatan pasien } \\
\text { dan keluarga yang } \\
\text { hilang }\end{array}$ \\
\hline 7 & $\begin{array}{l}\text { Istiqomah dan } \\
\text { Rochmah, } 2016\end{array}$ & Indonesia & Pasien & Biaya perawatan, obat & - & $\begin{array}{l}\text { Biaya produktivitas } \\
\text { yang hilang, biaya } \\
\text { perjalanan, biaya } \\
\text { pendamping }\end{array}$ \\
\hline 8 & Le et al., 2012 & China & Pasien & $\begin{array}{l}\text { kunjungan rawat jalan } \\
\text { dan rawat inap, } \\
\text { pengobatan mandiri }\end{array}$ & $\begin{array}{l}\text { Biaya } \\
\text { perjalanan, } \\
\text { akomodasi, } \\
\text { pengasuh }\end{array}$ & $\begin{array}{l}\text { Biaya morbiditas dan } \\
\text { mortalitas }\end{array}$ \\
\hline 9 & Nguyen et al., 2014 & Vietnam & $\begin{array}{l}\text { Penyedia layanan } \\
\text { kesehatan }\end{array}$ & $\begin{array}{l}\text { rawat inap per hari, } \\
\text { obat, laboratorium }\end{array}$ & - & - \\
\hline 10 & Suhil et al., 2010 & Malaysia & $\begin{array}{c}\text { Penyedia layanan } \\
\text { kesehatan }\end{array}$ & $\begin{array}{l}\text { obat, waktu tenaga } \\
\text { kesehatan }\end{array}$ & - & - \\
\hline II & $\begin{array}{l}\text { Utari dan Rochmah, } \\
2017\end{array}$ & Indonesia & Pasien & $\begin{array}{l}\text { perawatan rawat inap } \\
\text { dan rawat jalan }\end{array}$ & - & $\begin{array}{l}\text { Produktivitas pasien } \\
\text { dan keluarga yang } \\
\text { hilang, biaya } \\
\text { perjalanan (baik di } \\
\text { rawat jalan dan } \\
\text { rawat inap) }\end{array}$ \\
\hline 12 & $\begin{array}{l}\text { Zawudie et al., } \\
2020\end{array}$ & Ethiopia & Pasien & $\begin{array}{l}\text { obat, tes laboratorium, } \\
\text { Biaya pendaftaran }\end{array}$ & $\begin{array}{l}\text { makan, } \\
\text { perjalanan }\end{array}$ & $\begin{array}{l}\text { Pendapatan pasien } \\
\text { yang hilang }\end{array}$ \\
\hline
\end{tabular}


Tabel II. Komponen penyusun biaya berdasarkan perspektif

\begin{tabular}{|c|c|c|c|c|c|}
\hline Perspektif & & Masyarakat & Pasien & $\begin{array}{c}\text { Penyedia } \\
\text { Layanan } \\
\text { Kesehatan }\end{array}$ & Pembayar \\
\hline \multirow{6}{*}{ Biaya Medis Langsung } & Biaya Obat & + & + & + & + \\
\hline & Biaya Konsultasi Dokter & + & + & + & + \\
\hline & $\begin{array}{l}\text { Biaya Pemeriksaan Penunjang } \\
\text { (Tes Laboratorium) }\end{array}$ & + & + & + & + \\
\hline & $\begin{array}{c}\text { Biaya Tenaga Kesehatan Yang } \\
\text { Merawat }\end{array}$ & + & + & + & + \\
\hline & Biaya Administrasi & + & + & + & + \\
\hline & Biaya Tambahan Lainnya & - & + & - & - \\
\hline \multirow{2}{*}{$\begin{array}{l}\text { Biaya Non Medis } \\
\text { Langsung }\end{array}$} & Biaya Perjalanan & + & + & - & - \\
\hline & Biaya Makan & + & + & - & - \\
\hline \multirow{2}{*}{ Biaya Tidak langsung } & Biaya Morbiditas & + & + & - & - \\
\hline & Biaya Mortalitas & + & + & - & - \\
\hline
\end{tabular}

Komponen biaya kesehatan pada perspektif masyarakat dan pasien adalah biaya medis dan non medis langsung serta biaya tidak langsung. Komponen biaya pada perspektif pembayar adalah biaya medis dan non medis langsung. Perspektif penyedia layanan kesehatan hanya menghitung biaya medis langsung (Rascati, 2014).

\section{Biaya Medis Langsung}

Berdasarkan 12 artikel yang ditemukan dari berbagai negara, diketahui bahwa terdapat kesamaan dalam mengidentifikasi komponen biaya medis langsung. Pada pelayanan rawat inap ataupun rawat jalan, biaya obat, konsultasi dokter, pemeriksaan penunjang (tes laboratorium), tenaga kesehatan yang merawat, administrasi merupakan biaya yang dihitung sebagai biaya medis langsung. Menurut Etika et al. (2020) bahwa frekuensi kedatangan pasien ke fasilitas kesehatan dan kepatuhan pasien dalam pengobatan memiliki konsekuensi pada pengeluaran biaya kesehatan. Penyakit hipertensi yang tidak terkontrol dengan obat-obatan dapat memicu pasien untuk mencari perawatan di luar fasilitas kesehatan formal dan memicu perburukan penyakit (Etika et al., 2020). Menurut Alefan et al. (2009) bahwa biaya konsultasi dokter menjadi biaya tertinggi dikarenakan perawatan penyakit hipertensi dibedakan sesuai dengan derajat keparahannya. Pencapaian target tekanan darah pasien membutuhkan waktu, keahlian dokter dan biaya yang besar untuk mencari jenis obat yang mampu menurunkan hipertensi. Jenis obat antihipertensi dapat dimulai dari monoterapi, kombinasi 2 macam obat dan kombinasi $\geq 3$ macam obat. Biaya obat tertinggi adalah kombinasi herbesser $C D$ dan candesartan yaitu sebesar Rp 434.632,00 sedangkan biaya obat terendah adalah kombinasi amlodipin + spironolakton + candesartan yaitu sebesar Rp2I3.284,00 (Baroroh \& Fathonah, 2017). Biaya ini perlu ditekan agar tidak menjadi beban ekonomi melalui modifikasi gaya hidup seperti menurunkan asupan sodium, mengendalikan berat badan, berhenti merokok dan konsumsi alkohol serta penggunaan obat antihipertensi secara rutin untuk menurukan risiko komplikasi kardiovaskular (Alefan et al., 2009).

Menurut Baroroh dan Fathonah (2017) bahwa biaya administrasi dihitung sebagai konsekuensi menjadi pasien fasilitas layanan kesehatan yang terdiri dari biaya pendaftaran rawat jalan atau rawat inap, biaya jasa pengambilan obat dan embalase serta tuslah per lembar resep. Biaya administrasi bervariasi sesuai dengan kebijakan rumah sakit. 
Tabel III. Besar biaya langsung dan tidak langsung yang dikeluarkan

\begin{tabular}{|c|c|c|c|c|}
\hline \multirow[t]{2}{*}{ No } & \multirow[t]{2}{*}{ Nama Peneliti } & \multirow[t]{2}{*}{ Tahun } & \multicolumn{2}{|c|}{ Komponen Biaya dari Biaya Total } \\
\hline & & & Biaya Langsung & Biaya Tidak Langsung \\
\hline I & Adane et al. & 2020 & $72,98 \%$ & $27 \%$ \\
\hline 2 & Alefan et al. & 2009 & RM 27I8.2I & RM 75II.4I \\
\hline 3 & Aminde et al. & 2021 & $46,4 \%$ & - \\
\hline 4 & Aslam et al. & 2018 & $97,1 \%$ & $0,02 \%$ \\
\hline 5 & Baroroh dan Fathonah & 2017 & Rp 213.284- Rp 434.632 per bulan & - \\
\hline 6 & Etika et al. & 2020 & Rp 36.140- Rp 2.744.000 per tahun & Rp 0- Rp 3.000.000 per tahun \\
\hline 7 & Istiqomah dan Rochmah & 2016 & Rp I57.600 & Rp 674.980 \\
\hline 8 & Le et al. & 2012 & $53,4 \%$ & $3,1 \%$ \\
\hline 9 & Nguyen et al. & 2014 & $\begin{array}{l}41,37 \% \text { untuk rawat inap } \\
33,96 \% \text { untuk obat } \\
22,55 \% \text { untuk laboratorium }\end{array}$ & - \\
\hline 10 & Suhil et al. & 2010 & $\begin{array}{l}\text { RM I I 4.654,86 untuk tahun } 2005 \\
\text { RM I I 6.822,55 untuk tahun } 2006\end{array}$ & - \\
\hline II & Utari dan Rochmah & 2017 & Rp 533.910 per kunjungan & Rp 532.65I per kunjungan \\
\hline 12 & Zawudie et al. & 2020 & $51 \%$ & $49 \%$ \\
\hline
\end{tabular}

Menurut Nguyen et al. (20/4), biaya pemeriksaan penunjang seperti biaya tes laboratorium terdiri atas jumlah reagen kimia yang digunakan, waktu yang digunakan staf laboratorium untuk pemeriksaan, jenis dan harga tes yang diambil. Biaya pengobatan hipertensi dan gangguan metabolisme sphingolipid serta penyimpanan lemak menjadi pertimbangan bagi pembayar untuk penetapan paket manfaat. Biaya perawatan hipertensi untuk rawat inap akibat tidak terkendali dan terobati memiliki kontribusi tinggi pada komponen biaya total (Nguyen et al., 20l4).

Biaya jasa tenaga kesehatan dihitung berdasarkan waktu yang diberikan oleh tenaga kesehatan (dokter, apoteker, perawat) untuk melayani pasien dibandingkan dengan pendapatan per bulan yang diperoleh masing-masing staf tenaga kesehatan. Berdasarkan tabel III diketahui bahwa sebagian besar penelitian menyatakan jika biaya langsung yang terdiri dari biaya medis dan non medis memberikan porsi besar dalam pengeluaran biaya kesehatan yaitu $>45 \%$.

\section{Biaya Non Medis Langsung}

Biaya perjalanan merupakan komponen biaya non medis langsung yang sering diteliti, diikuti dengan biaya makan. Menurut Adane et al. (2020) bahwa sebesar $12,17 \%$ dikeluarkan untuk biaya perjalanan. Hal ini dikarenakan 85,1\% partisipan tinggal di daerah pedesaan dan kemudahan akses ke fasilitas layanan kesehatan yang berjarak $4 \mathrm{~km}$ dari rumah (Adane et al., 2020). Biaya makan dikeluarkan sebesar $25 \%$ dari total biaya untuk pasien ataupun pendamping saat kontrol hipertensi dan menjadi biaya tertinggi kedua setelah biaya obat (Zawudie et al., 2020).

Namun, kesamaan pemahaman terhadap biaya non medis langsung masih belum terjadi. Hal ini terlihat dari 2 artikel yang dilakukan di Indonesia mengkategorikan biaya perjalanan ke dalam biaya tidak langsung (Istiqomah \& Rochmah, 2016; Utari \& Rochmah, 2017). Oleh karena itu, review ini bertujuan untuk memberikan persepsi yang sama terhadap pengelompokan biaya langsung dan tidak langsung di sektor layanan kesehatan.

\section{Biaya Tidak Langsung}

Produktivitas yang hilang dari pasien/ pengasuh menjadi komponen biaya tidak langsung. Biaya ini dihitung dengan pendekatan human capital . Penilaian biaya ini berdasarkan waktu pasien/ pengasuh yang hilang karena mengantar periksa ke fasilitas layanan kesehatan dalam bentuk unit moneter (Zawudie et al., 2020).

Penelitian yang dilakukan Zawudie et al. (2020) menjelaskan bahwa biaya tidak langsung terkait dengan waktu perjalanan dan tidak masuk kerja untuk pengobatan penyakit hipertensi adalah sebesar $49 \%$. Sebagian besar partisipan yang tinggal dengan jarak $>10$ $\mathrm{km}$ dari fasilitas layanan kesehatan cenderung jarang memeriksakan diri dengan rutin sehingga pemanfaatan layanan rendah. Hal ini menuntut pemerintah untuk 
meningkatkan jangkauan dan pemerataan layanan sehingga hipertensi dapat terkendali dan menurunkan beban ekonomi (Zawudie et al., 2020).

Penelitian Le et al. (2012) menemukan bahwa biaya morbiditas sebesar $2,6 \%$ dari biaya total berupa kecacatan dan absen kerja akibat hipertensi. Selain itu, biaya mortalitas sebesar $0,5 \%$ dari biaya total berupa kematian dini (Le et al., 20I2).

\section{KESIMPULAN}

Berdasarkan hasil review diketahui bahwa komponen penyusun biaya kesehatan pada penyakit hipertensi ditentukan oleh perspektif dari pasien, penyedia layanan kesehatan dan pembayar. COI dapat membantu pembuat kebijakan memahami keseluruhan beban ekonomi, mempertimbangkan paket manfaat untuk tambahan cakupan asuransi kesehatan, mengendalikan perburukan penyakit dengan upaya promotif dan preventif serta meningkatkan program kesehatan publik pemerintah bagi penyakit hipertensi. Hasil review ini berguna bagi peneliti lainnya untuk mengembangkan penelitian $\mathrm{COI}$ tentang penyakit kronis. Data biaya dari COI dapat menjadi input untuk penelitian farmakoekonomi dengan metode lainnya.

\section{UCAPAN TERIMA KASIH}

Ucapan terima kasih kepada seluruh sivitas akademika Universitas Gadjah Mada yang telah mendukung peneliti dalam proses penelitian.

\section{REFERENSI}

I. Adane, E., Atnafu, A., \& Aschalew, A. Y. (2020). The Cost of Illness of Hypertension and Associated Factors at the University of Gondar Comprehensive Specialized Hospital Northwest Ethiopia, 2018. ClinicoEconomics and Outcomes Research, Volume I2, I33-I40. https://doi.org//0.2147/CEOR.S234674

2. World Health Organization. (2019). Hypertension. https://www.who.int/westernpacific/healthtopics/hypertension
3. Badan Penyelenggara Jaminan Sosial Kesehatan. (2019). Peraturan Badan Penyelenggara Jaminan Sosial Kesehatan Nomor 2 Tahun 2019 Tentang Pelaksanaan Skrining Riwayat Kesehatan Dan Pelayanan Penapisan Atatu Skrining Kesehatan Tertentu Serta Peningkatan Kesehatan Bagi Peserta Penderita Penyakit Kronis Dalam Program Jaminan Kesehatan.

4. Kementerian Kesehatan Republik Indonesia. (2019). Hipertensi Penyakit Paling Banyak Diidap Masyarakat.

https://www.kemkes.go.id/article/view/ I90517000

02/hipertensi-penyakit-paling-banyak-diidapmasyarakat.html

5. Meiriana, A., Trisnantoro, L., \& Padmawati, R. S. (2019). Implementasi Program Pengelolaan Penyakit Kronis (Prolanis) Pada Penyakit Hipertensi Di Puskesmas Jetis Kota Yogyakarta. Jurnal Kebijakan Kesehatan Indonesia: JKKI, 8(2), $5 \mathrm{I}-58$.

6. Istiqomah, A. N., \& Rochmah, T. N. (20I6). Beban Ekonomi Pada Penderita Hipertensi Dengan Status Pbi Jkn Di Kabupaten Pamekasan. Jurnal Manajemen Kesehatan Yayasan RS.Dr. Soetomo, 2(2),

124-132. https://doi.org//0.2924I/jmk.v2i2.58

7. Aregbeshola, B. S., \& Khan, S. M. (2018). Out-ofPocket Payments, Catastrophic Health Expenditure and Poverty Among Households in Nigeria 2010. International Journal of Health Policy and Management, 7(9), 798-806. https://doi.org/10.15171/ijhpm.2018.19

8. Le, C., Zhankun, S., Jun, D., \& Keying, Z. (20I2). The economic burden of hypertension in rural south-west China. Tropical Medicine \& International Health, I7(I2), |544-|55|. https://doi.org/I0.1 I I I/j.|365-3/56.2012.03087.x

9. Baroroh, F., \& Fathonah, S. S. (20I7). Biaya Medik Langsung Terapi Hipertensi Pasien Rawat Jalan DI Rumah Sakit $X$ Yogyakarta. Jurnal Farmasi Sains dan Praktis, 3(2), 6-13. https://doi.org/10.31603/pharmacy.v3i2.1724

10. Alefan, Q., Ibrahim, M. I. M., Razak, T. A., \& Ayub, A. (2009). Cost Of Treating Hypertension In Malaysia. Asian Journal of Pharmaceutical and Clinical Research, 2(I), I-5.

II. Aminde, L. N., Dzudie, A., Mapoure, Y. N., Tantchou, J. C., \& Veerman, J. L. (202I). Estimation and determinants of direct medical costs of ischaemic heart disease, stroke and hypertensive heart disease: Evidence from two major hospitals in Cameroon. BMC Health Services 
Research, $2 I(1), \quad 140$. https://doi.org/|0.1|86/s|29|3-021-06|46-4

12. Aslam, N., Shoaib, M. H., Bushra, R., Farooqi, F. A., Zafar, F., Ali, H., \& Saleem, S. (20I8). Out of pocket (OOP) cost of treating hypertension in Karachi, Pakistan. Pak. J. Pharm. Sci., 6.

13. Nguyen, T.-P.-L., Nguyen, T. B. Y., Nguyen, T. T., Vinh Hac, V., Le, H. H., Schuiling-Veninga, C., \& Postma, M. J. (20|4). Direct costs of hypertensive patients admitted to hospital in Vietnam' a bottom-up micro-costing analysis. BMC Health Services Research, I4(I), 514. https://doi.org/|0.1|86/s 129|3-0|4-05|4-4

14. Rascati, K. L. (20|4). Essentials of pharmacoeconomics (Second edition). Wolters Kluwer Health/Lippincott Williams \& Wilkins.

15. Afroz, A., Alramadan, M. J., Hossain, M. N., Romero, L., Alam, K., Magliano, D. J., \& Billah, B. (2018). Cost-of-illness of type 2 diabetes mellitus in low and lower-middle income countries: A systematic review. BMC Health Services Research, I8(I), 972. https://doi.org//0.1/86/s/29/3-0183772-8

16. Etika, T., Pristianty, Liza, \& Ratna Hidayati, I. (2020). Analisis Cost of Illness Pada Pasien Hipertensi Peserta BPJS Rawat Jalan di Puskesmas Banyuanyar. Pharmaceutical Journal of Indonesia, 6(I), $4 I-46$. https://doi.org/I0.21776/ub.pji.2020.006.01.7

17. Suhil, M. A., Hassali, M. A. A., \& Ibrahim, M. I. M. (2010). Evaluation of Direct Medical Cost In Treating Hypertension In A Malaysian Public University. Asian Journal of Pharmaceutical and Clinical Research, 3(3), I70-173.

18. Utari, A. B., \& Rochmah, T. N. (20I7). Cost of Hypertension Disease in Kediri Regency. Proceedings of the 4th Annual Meeting of the Indonesian Health Economics Association, 272-276. https://doi.org// 0.5220/0007028702720276

19. Zawudie, A. B., Lemma, T. D., \& Daka, D. W. (2020). Cost of Hypertension Illness and Associated Factors Among Patients Attending Hospitals in Southwest Shewa Zone, Oromia Regional State, Ethiopia. ClinicoEconomics and Outcomes Research, Volume 12, 20I-2II. https://doi.org/I0.2 I47/CEOR.S24I59| 